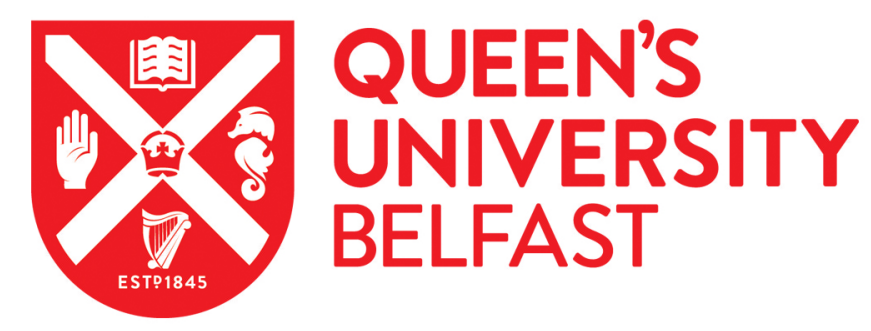

\title{
International differences in lung cancer survival by sex, histological type and stage at diagnosis; an ICBP SURVMARK-2 Study
}

ICBP SURVMARK-2 Local Leads (2021). International differences in lung cancer survival by sex, histological type and stage at diagnosis; an ICBP SURVMARK-2 Study. Thorax. https://doi.org/10.1136/thoraxjnl-2020216555

\section{Published in:}

Thorax

\section{Document Version:}

Peer reviewed version

Queen's University Belfast - Research Portal:

Link to publication record in Queen's University Belfast Research Portal

\section{Publisher rights}

Copyright 2021 BMJ. This manuscript is distributed under a Creative Commons Attribution-NonCommercial License

(https://creativecommons.org/licenses/by-nc/4.0/), which permits use, distribution and reproduction for non-commercial purposes, provided the author and source are cited.

\section{General rights}

Copyright for the publications made accessible via the Queen's University Belfast Research Portal is retained by the author(s) and / or other copyright owners and it is a condition of accessing these publications that users recognise and abide by the legal requirements associated with these rights.

Take down policy

The Research Portal is Queen's institutional repository that provides access to Queen's research output. Every effort has been made to ensure that content in the Research Portal does not infringe any person's rights, or applicable UK laws. If you discover content in the Research Portal that you believe breaches copyright or violates any law, please contact openaccess@qub.ac.uk. 


\section{International differences in lung cancer survival by sex, histological type and stage at diagnosis: an ICBP SUVRMARK-2 study}

Marzieh Araghi ${ }^{1 *}$, Miranda M Fidler-Benaoudia ${ }^{2^{*}}$, Melina Arnold ${ }^{1}$, Mark Rutherford ${ }^{1,3}$, Aude Bardot $^{1}$, Jacques Ferlay ${ }^{1}$, Oliver Bucher ${ }^{4}$, Prithwish De ${ }^{5}$, Gerda Engholm ${ }^{6}$, Anna Gavin ${ }^{7}$, Serena Kozie $^{8}$, Alana Little ${ }^{9}$, Bjørn Møller ${ }^{10}$, Nathalie Saint-Jacques ${ }^{11}$, Hanna Tervonen ${ }^{9}$, Paul Walsh ${ }^{12}$, Ryan Woods ${ }^{13,14}$, Dianne O'Connell15, David Baldwin ${ }^{16}$, Mark Elwood ${ }^{17}$, Sabine Siesling ${ }^{18}$, Freddie Bray $^{1}$, Isabelle Soerjomataram ${ }^{1}$

${ }^{*}$ Authors have contributed equally to the paper

${ }^{1}$ Section of Cancer Surveillance, International Agency for Research on Cancer, 150 Cours Albert Thomas, Lyon, 69372 CEDEX 08, France

${ }^{2}$ Cancer Epidemiology and Prevention Research, Holy Cross Centre, Calgary AB T2S 3C3,

Canada

${ }^{3}$ Department of Health Sciences, University of Leicester, University Road, Leicester, LE1 7RH, United Kingdom

${ }^{4}$ Department of Epidemiology and Cancer Registry, Cancercare Manitoba, MB, Canada

${ }^{5}$ Analytics and Informatics, Cancer Care Ontario, Toronto, Canada.

${ }^{6}$ Cancer Surveillance and Pharmacoepidemiology, Danish Cancer Society Research Center, Copenhagen, Denmark

${ }^{7}$ Northern Ireland Cancer Registry, Queen's University Belfast, Belfast, Northern Ireland ${ }^{8}$ Saskatchewan Cancer Agency 200-4545 Parliament Avenue Regina, SK S4W 0G3, Canada

${ }^{9}$ Cancer Institute New South Wales (NSW), PO Box 41, Alexandria NSW 1435, Australia

${ }^{10}$ Department of Registration, Cancer Registry of Norway, Oslo, Norway

${ }^{11}$ Nova Scotia Health Authority Cancer Care Program, Registry \& Analytics, 1276 South Street, Halifax, B3H 2Y9, NS, Canada

12 National Cancer Registry Ireland, Cork Airport Business Park, Kinsale Road, Cork T12 CDF7, Ireland.

${ }^{13}$ BC Cancer, Vancouver, British Columbia, Canada

${ }^{14}$ Faculty of Health Sciences, Simon Fraser University, Burnaby, BC V5A 1S6, Cancer Control Research, BC Cancer, Vancouver, BC V5Z 1L3, Canada

${ }^{15}$ Cancer Research Division, Cancer Council NSW, Sydney, New South Wales, Australia

${ }^{16}$ Respiratory Medicine Unit, David Evans Centre, Nottingham City Hospital, Hucknall Road, Nottingham, NG5 1PB, UK 
17 School of Population Health, University of Auckland, Auckland, New Zealand

18 Department of Research and Development, Netherlands Comprehensive Cancer Centre Organisation, PO Box 19079, 3501 DB Utrecht, the Netherlands

\section{Correspondence to:}

Isabelle Soerjomataram, MD PhD

Section of Cancer Surveillance, International Agency for Research on Cancer (IARC/WHO)

150 Cours Albert Thomas, 69008 Lyon, France

soerjomatarami@iarc.fr

Word count: 3378 


\section{Key messages}

What is the key question?

Are there international disparities in lung cancer survival by clinically-relevant subgroups in the most recent population level data?

What is the bottom line?

International differences in survival among patients with lung cancer persist in high-income countries, which are partly due to differences in stage at diagnosis or early detection, and to survival difference within stage groups due to cancer management.

\section{Why read on?}

This study presents in-depth results of the most-up-to-date differences of lung cancer stage distribution and survival by histological types, age group and sex for each included country, as well as within countries, followed by a discussion of potential causes of the disparities including clinical and data factors. 


\section{ABSTRACT}

Introduction: Lung cancer has a poor prognosis that varies internationally when assessed by the two major histological subgroups [non-small cell (NSCLC) and small cell (SCLC)].

Method: 236,114 NSCLC and 43,167 SCLC cases diagnosed during 2010-2014 in Australia, Canada, Denmark, Ireland, New Zealand, Norway, and the United Kingdom (UK) were included in the analyses. One- and 3-year age-standardised net survival (NS) was estimated by sex, histological type, stage, and country.

Results: One- and 3-year NS was consistently higher for Canada and Norway, and lower for the UK, New Zealand and Ireland, irrespective of stage at diagnosis. Three-year NS for NSCLC ranged from $19.7 \%$ for the UK to $27.1 \%$ for Canada for males and was consistently higher for females (25.3\% in the UK; $35.0 \%$ in Canada) partly because males were diagnosed at more advanced stages. International differences in survival for NSCLC were largest for regional stage and smallest at the advanced stage. For SCLC, 3-year NS also showed a clear female advantage with the highest being for Canada (13.8\% for females; $9.1 \%$ for males) and Norway (12.8\% for females; $9.7 \%$ for males).

Conclusion: Distribution of stage at diagnosis among lung cancer cases differed by sex, histological subtype and country, which may partly explain observed survival differences. Yet, survival differences were also observed within stages, suggesting that quality of treatment, healthcare system factors, and prevalence of comorbid conditions may also influence survival. Other possible explanations include differences in data collection practice, as well as differences in histological verification, staging and coding across jurisdictions.

Keywords: Histology, lung cancer, stage at diagnosis, survival, international 


\section{INTRODUCTION}

Lung cancer is the leading cause of cancer death among men and women worldwide, with an estimated 1.6 million deaths, or nearly $20 \%$ of all cancer deaths, occurring in $2018 .{ }^{1}$ Lung cancer is categorised into two main histological groups - small cell lung carcinoma (SCLC) and non-small cell lung carcinoma (NSCLC) - with SCLC patients generally having poorer outcomes compared to NSCLC. ${ }^{2}$ Marked sex differences in survival have also been previously reported, with females having a more favourable prognosis. ${ }^{3-6}$

As cancer survival is one of the key measures of performance improvement in health care, international cancer survival comparisons can identify possible causes for observed variations, such as access to early detection or optimal treatments. The International Cancer Benchmarking Partnership (ICBP), a consortium of clinicians, policy-makers, researchers, and cancer data experts, has previously described lung cancer survival differences across high-income countries ${ }^{7}$ and concluded that stage at diagnosis and histological type explained some of the international variation in lung cancer survival in 2004-2007. ${ }^{2}$ In this study, we extend this prior work by assessing the most up-to-date lung cancer survival statistics by sex and stage at diagnosis for NSCLC and SCLC, using population-based data from seven countries.

\section{METHODS}

\section{Data}

Data were collected as part of the ICBP SURVMARK-2 project for patients diagnosed during 1995-2014 at ages above 18 years and followed until the end of 2015. ${ }^{8}$ ICBP countries were included due to their high-quality population-wide registries, universal access to healthcare with similar healthcare expenditure, and interest in understanding how and why cancer survival differs across countries. For this study, lung carcinoma data from 18 population-based cancer registries in seven countries with at least $50 \%$ complete data on stage at diagnosis during 2010-2014, were included (Australia - New South Wales; Canada - Alberta, British Columbia, Manitoba, New Brunswick, Newfoundland, Nova Scotia, Ontario, Prince Edward Island, Saskatchewan; Denmark; Ireland (2010-2013); New Zealand; Norway; and the UK - England, Scotland, Wales, Northern Ireland). Cases diagnosed with an invasive primary malignant tumour of the lung and bronchus (ICD-10: C34) were classified as SCLC, NSCLC, other and unspecified histology (see Table 1). Of 393,453 adult lung cancer patients diagnosed during 2010-2014, we excluded cases diagnosed based on death certificate only (DCO) or at autopsy $(\mathrm{N}=8,105,2.1 \%)$, with inconsistent 
dates $(\mathrm{N}=54,<0.0 \%)$, below age 15 or above age $99(\mathrm{~N}=127,<0.0 \%)$, with second primary cancer in the lung $(\mathrm{N}=5,034,1.3 \%)$, with incorrect stage information $(\mathrm{N}=4,557,1.2 \%)$ or classified as neuroendocrine neoplasms (NEN) $(\mathrm{N}=7,869,2.0 \%)$.

Each participating cancer registry provided information on pre-treatment pathological and clinical stage based on the tumour extent $(\mathrm{T})$, the degree of nodal involvement $(\mathrm{N})$, and the presence of metastases (M), grouped TNM (stages I-IV), and SEER summary stage 2000 (Supplementary Figure 1A). A previously developed algorithm ${ }^{9}$ was adapted to harmonise individual or grouped TNM information $\left(7^{\text {th }}\right.$ edition ${ }^{10}$ ) to SEER stage (localised, regional, distant and missing), creating a 'mapped SEER stage' that combines both TNM and SEER stage information; during the stage mapping, pathological $\mathrm{T}$ and $\mathrm{N}$, and clinical $\mathrm{M}$ information was prioritised if both pathological and clinical data were available (Supplementary Figure 1B).

\section{Statistical analyses}

We estimated net survival, which is the survival of cancer patients after adjustments for background mortality in the general population using life tables. Life tables were specific to sex, single year of age, geographical region and year of death. Net survival estimates at one and three years after diagnosis were estimated by histological group and sex for each country and jurisdiction, as appropriate, using Pohar Perme estimators. ${ }^{11}$ Age-standardisation was carried out using International Cancer Survival Standard weights. ${ }^{12}$ The period approach was used to provide short-term predictions of three-year survival for patients diagnosed during 2010-2014. Statistically significant differences in net survival between sexes, histological subgroups, countries or jurisdictions were determined by comparing the $95 \%$ confidence intervals $(95 \% \mathrm{Cl})$.

Stage at diagnosis was imputed separately for SCLC and NSCLC patients with missing stage data (SCLC missingness range: $1.1 \%$ (Denmark - SEER) to $33.6 \%$ (UK - TNM); NSCLC missing range: $1.1 \%$ (Denmark -SEER) to $33.3 \%$ (UK - TNM). Covariates in the imputation model included age, sex, year of diagnosis, survival time, and the Nelson-Aalen estimator of the cumulative hazard. We ran the imputation model 30 times and combined the results using Rubin's rules. ${ }^{13}$ Stage-specific survival estimates using the imputed datasets were then compared with the corresponding results without imputation (Supplementary Tables $1 \& 2$ ). All analyses were undertaken using Stata $14 .{ }^{14}$ 
Final results are presented by grouped TNM for all countries except Australia and New Zealand where TNM data were not collected, and mapped SEER stage for all countries, and stratified by histology group. All results relate to imputed stage, unless otherwise noted. For simplicity, we used stages I-IV when referring to TNM stage, and 'localised', 'regional', and 'distant' when referring to mapped SEER stage. Finally, while we focussed on sex-specific estimates, the findings for both sexes combined are presented in Supplementary Figures 2-5 and Supplementary Tables 1-10.

\section{RESULTS}

In total, 367,707 patients (93.5\%) diagnosed during 2010-2014 were included in the survival analyses (Table 1). 280,744 cases ( $76.4 \%$ of eligible cases) were microscopically confirmed, either through cytologic examination, histology of primary tumour or of metastasis. The proportion with NSCLC ranged between 59\% (UK) and 76\% (Australia) while the proportion with SCLC was largely consistent across all countries at $11-12 \%$, with a slightly larger proportion in Denmark (14\%) and Norway (16\%). The proportion with unspecified cancers ranged from $11 \%$ (Denmark) to $29 \%$ (UK). For the remainder of this report we will comment only on results for NSCLC and SCLC cases $(n=279,281)$. 
Table 1. Characteristics of patients diagnosed with lung cancer during 2010-2014

\begin{tabular}{|c|c|c|c|c|c|c|c|c|}
\hline & Australia $^{\circ}$ & Canada $^{\dagger}$ & Denmark & Ireland ${ }^{\mathbb{I}}$ & $\begin{array}{c}\text { New } \\
\text { Zealand } \\
\end{array}$ & Norway & $\begin{array}{c}\text { United } \\
\text { Kingdom }\end{array}$ & Total \\
\hline Number of patients diagnosed during 2010-2014 & 18,567 & 90,439 & 22,828 & 9,393 & 10,309 & 14,538 & 227,379 & 393,453 \\
\hline \multicolumn{9}{|l|}{ Exclusions } \\
\hline Diagnosed based on death certificate only (DCO) or autopsy & $665(3.6 \%)$ & $1,412(1.6 \%)$ & $272(1.2 \%)$ & $157(1.7 \%)$ & $185(1.8 \%)$ & $334(2.3 \%)$ & $5,080(2.2 \%)$ & $8,105(2.1 \%)$ \\
\hline Quality control $^{\Delta}$ & $48(0.3 \%)$ & $5(0.0 \%)$ & None & None & None & None & $1(0.0 \%)$ & $54(0.0 \%)$ \\
\hline Age $<15$ or $>99$ years & $4(0.0 \%)$ & $20(0.0 \%)$ & $1(0.0 \%)$ & $2(0.0 \%)$ & $1(0.0 \%)$ & $4(0.0 \%)$ & $95(0.0 \%)$ & $127(0.0 \%)$ \\
\hline Second or higher order cancers at the same site & $89(0.5 \%)$ & $1,478(1.6 \%)$ & $78(0.3 \%)$ & $187(2.0 \%)$ & $2(0.0 \%)$ & $172(1.2 \%)$ & $3,028(1.3 \%)$ & $5,034(1.3 \%)$ \\
\hline Cases with inconsistencies in stage information* & None & $174(0.2 \%)$ & $801(3.5 \%)$ & $204(2.2 \%)$ & None & $292(2.0 \%)$ & $3,086(1.4 \%)$ & $4,557(1.2 \%)$ \\
\hline Neuroendocrine Neoplasms (NENs) ${ }^{\diamond}$ & $451(2.4 \%)$ & $1,846(2.0 \%)$ & $629(2.8 \%)$ & $270(2.9 \%)$ & $181(1.8 \%)$ & $371(2.6 \%)$ & $4,121(1.8 \%)$ & $7,869(2.0 \%)$ \\
\hline Total cases eligible for survival analysis & $17,310(93.2 \%)$ & $85,504(94.5 \%)$ & $21,047(92.2 \%)$ & $8,573(91.3 \%)$ & $9,940(96.4 \%)$ & $13,365(91.9 \%)$ & $211,968(93.2 \%)$ & $367,707(93.5 \%)$ \\
\hline$\%$ Males & $59.1 \%$ & $51.9 \%$ & $51.1 \%$ & $56.6 \%$ & $52.7 \%$ & $55.2 \%$ & $54.4 \%$ & $53.9 \%$ \\
\hline \multicolumn{9}{|l|}{ Histological subtype } \\
\hline $\operatorname{SCLC}^{\bar{\top}}$ & $1,971(11.4 \%)$ & $9,671(11.3 \%)$ & $2,991(14.2 \%)$ & $1,089(12.7 \%)$ & $1,185(11.9 \%)$ & $2,097(15.7 \%)$ & $24,163(11.4 \%)$ & $43,167(11.7 \%)$ \\
\hline NSCLC ${ }^{\S}$ & $13,115(75.8 \%)$ & $59,969(70.1 \%)$ & $15,590(74.1 \%)$ & $6,006(70.1 \%)$ & $6,619(66.6 \%)$ & $9,414(70.4 \%)$ & $125,401(59.2 \%)$ & $236,114(64.2 \%)$ \\
\hline Other ${ }^{\partial}$ & $44(0.3 \%)$ & $119(0.1 \%)$ & $62(0.3 \%)$ & $19(0.2 \%)$ & $23(0.2 \%)$ & $30(0.2 \%)$ & $403(0.2 \%)$ & $700(0.2 \%)$ \\
\hline Unspecified $^{A}$ & $2,180(12.6 \%)$ & $15,745(18.4 \%)$ & 2,404 (11.4\%) & $1,459(17.0 \%)$ & $2,113(21.3 \%)$ & $1,824(13.6 \%)$ & 62,001 (29.3\%) & 87,726 (23.9\%) \\
\hline
\end{tabular}

${ }^{\dagger}$ Canadian provinces included: Alberta, British Columbia, New Brunswick, Manitoba, Newfoundland, Nova Scotia, Ontario, Prince Edward Island, and Saskatchewan

${ }^{\ddagger}$ United Kingdom registries included: England, Northern Ireland, Scotland, and Wales

${ }^{\circ}$ Australia registries included: New South Wales

9 Ireland (2010-2013)

${ }^{\Delta}$ Includes: data inconsistencies (invalid age, missing/incomplete dates), tumours with non-malignant behavior, tumours with invalid morphological or topographical codes

* Stage error or in situ flag

${ }^{\circ}$ NENs (ICD-O-3 morphology): 8013 and 8041-8045 (excluding lung cancer), 8150-8158, 8240-8247, 8249, 9091, 8574

${ }^{\top}$ SCLC, small cell lung cancer (ICD-O-3 morphology): 8041-8045

$\S$ NSCLC, non-small cell lung cancer (ICD-O-3 morphology): 8012, 8014, 8050-8078, 8083, 8084, 8140, 8211, 8230-8231, 8250-8260, 8323, 8480-8490, 8550-8552, 8570-8574, 8576

${ }^{\circ}$ Other, specified (ICD-O-3 morphology): 8800-8811, 8830, 8840-8921, 8990, 8991, 9040-9044, 9120-9133, 9150, 9540-9581

${ }^{A}$ Unspecified (ICD-O-3 morphology): 8000-8005, 8010, 8011 


\section{Non-Small Cell Lung Carcinoma}

At least $45 \%$ of the 236,114 NSCLC cases were diagnosed at the most advanced stage (Stage IV for TNM, distant stage for SEER) for males in all countries, with the largest proportion observed in New Zealand at 59.8\% (Table 2A, Figure 1A). Compared to males, females had a more favourable stage distribution in all countries, except New Zealand and Denmark (Table 2B, Figure 1A). 
Table 2A. Number and proportion of male patients with non-small cell lung carcinoma (NSCLC) and small cell lung carcinoma (SCLC) diagnosed during 2010-2014 by country and stage at diagnosis (TNM and SEER), before and after imputation

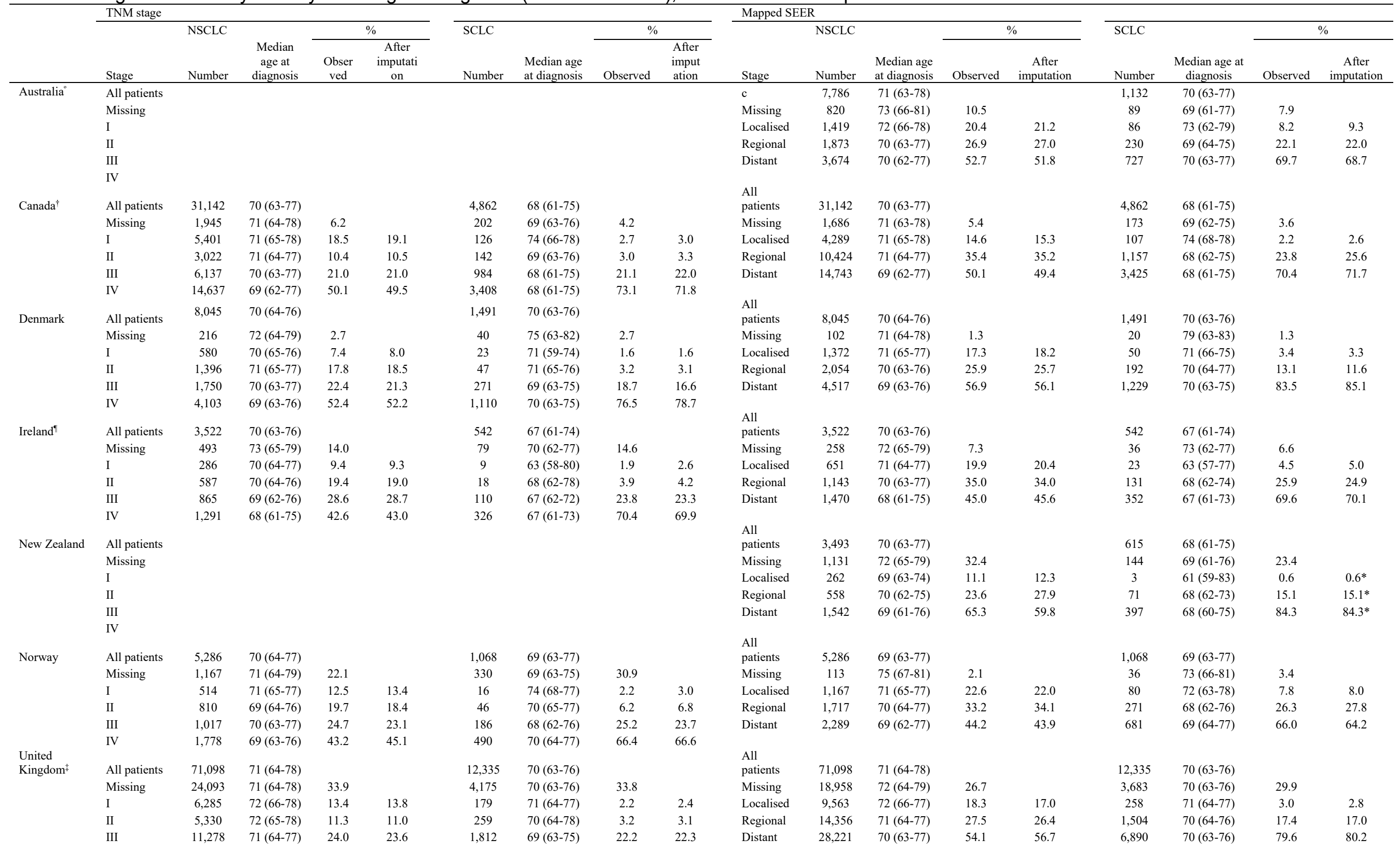


IV $\quad 24,112 \quad 70(63-77) \quad 51.3 \quad 51.6$

$5,910 \quad 70(63-76)$

Canadian provinces included: Alberta, British Columbia, New Brunswick, Manitoba, Nath
† United Kingdom registries included: England, Northern Ireland, Scotland, and Wales

- Australia registries included: New South Wales

"Ireland: 2010-2013

* Model did not converge

Table 2B. Number and proportion of female patients with non-small cell lung carcinoma (NSCLC) and small cell lung carcinoma (SCLC) diagnosed during 2010-2014 by country and stage at diagnosis (TNM and SEER), before and after imputation

\begin{tabular}{|c|c|c|c|c|c|c|c|c|c|c|c|c|c|c|c|c|c|c|}
\hline & \multicolumn{5}{|c|}{ TNM stage } & & & \multirow{2}{*}{\multicolumn{2}{|c|}{ SCLC }} & \\
\hline & \multirow[b]{2}{*}{ Stage } & \multirow{2}{*}{$\begin{array}{c}\text { NSCLC } \\
\text { Numbe } \\
\mathrm{r}\end{array}$} & \multirow[b]{2}{*}{$\begin{array}{l}\text { Median age } \\
\text { at diagnosis }\end{array}$} & \multicolumn{2}{|c|}{$\%$} & \multicolumn{2}{|l|}{ SCLC } & \multicolumn{2}{|c|}{$\%$} & \begin{tabular}{|l} 
Mapped SEER \\
NSCLC
\end{tabular} & \multicolumn{4}{|l|}{ NSCLC } & & & 0 & \\
\hline & & & & $\begin{array}{l}\text { Observe } \\
\quad \mathrm{d}\end{array}$ & $\begin{array}{c}\text { After } \\
\text { imputatio } \\
\text { n }\end{array}$ & Number & $\begin{array}{l}\text { Median age } \\
\text { at diagnosis }\end{array}$ & Observed & $\begin{array}{c}\text { After } \\
\text { imputati } \\
\text { on }\end{array}$ & Stage & Number & $\begin{array}{l}\text { Median age } \\
\text { at diagnosis }\end{array}$ & Observed & $\begin{array}{c}\text { After } \\
\text { imputation }\end{array}$ & Number & $\begin{array}{c}\text { Median age at } \\
\text { diagnosis }\end{array}$ & Observed & $\begin{array}{c}\text { After } \\
\text { imputati } \\
\text { on }\end{array}$ \\
\hline \multirow[t]{6}{*}{ Australia $^{\circ}$} & $\begin{array}{l}\text { All } \\
\text { patients }\end{array}$ & & & & & & & & & All patients & 5,329 & $69(62-77)$ & & & 839 & $69(61-76)$ & & \\
\hline & Missing & & & & & & & & & Missing & 536 & $72(64-81)$ & 10.1 & & 69 & $72(64-79)$ & 8.2 & \\
\hline & I & & & & & & & & & Localised & 1,095 & $71(64-77)$ & 22.8 & 24.9 & 83 & $69(60-76)$ & 10.8 & 11.5 \\
\hline & II & & & & & & & & & Regional & 1,272 & $69(62-76)$ & 26.5 & 26.6 & 206 & $69(60-76)$ & 26.8 & 25.2 \\
\hline & III & & & & & & & & & Distant & 2,426 & $68(60-77)$ & 50.6 & 48.5 & 481 & $68(61-75)$ & 62.5 & 63.3 \\
\hline & $\begin{array}{l}\text { IV } \\
\text { All }\end{array}$ & & & & & & & & & & & & & & & & & \\
\hline \multirow[t]{5}{*}{ Canada $\uparrow$} & $\begin{array}{l}\text { patients } \\
\text { Missing }\end{array}$ & $\begin{array}{c}28,827 \\
1,745\end{array}$ & $\begin{array}{l}69(62-76) \\
71(62-79)\end{array}$ & 6.1 & & $\begin{array}{c}4,809 \\
189\end{array}$ & $\begin{array}{l}69(61-75) \\
70(63-78)\end{array}$ & 3.9 & & $\begin{array}{l}\text { All patients } \\
\text { Missing }\end{array}$ & $\begin{array}{c}28,827 \\
1,534\end{array}$ & $\begin{array}{l}69(62-76) \\
71(62-78)\end{array}$ & 5.3 & & $\begin{array}{l}4,809 \\
155\end{array}$ & $\begin{array}{l}69(61-75) \\
70(63-77)\end{array}$ & 3.2 & \\
\hline & I & 6,421 & $70(63-76)$ & 23.7 & 25.0 & 155 & $72(63-77)$ & 3.4 & 3.8 & Localised & 5,072 & $70(63-77)$ & 18.6 & 19.8 & 129 & 71 (63-77) & 2.7 & 3.1 \\
\hline & II & 2,692 & $70(62-76)$ & 9.9 & 10.0 & 173 & $70(64-77)$ & 3.7 & 4.0 & Regional & 9,409 & $69(62-76)$ & 34.5 & 34.7 & 1,438 & $68(60-75)$ & 29.9 & 32.1 \\
\hline & III & 5,250 & $69(62-76)$ & 19.4 & 19.5 & 1,229 & $68(60-74)$ & 26.6 & 27.5 & Distant & 12,812 & $68(60-76)$ & 46.9 & 45.5 & 3,087 & $69(61-75)$ & 64.2 & 64.8 \\
\hline & IV & 12,719 & $68(60-76)$ & 47.0 & 45.5 & 3,063 & $69(61-75)$ & 66.3 & 64.7 & & & & & & & & & \\
\hline \multirow[t]{5}{*}{ Denmark } & $\begin{array}{l}\text { All } \\
\text { patients }\end{array}$ & 7,545 & $69(62-76)$ & & & 1,500 & $69(62-76)$ & & & All patients & 7,545 & $69(62-76)$ & & & 1,500 & $69(62-76)$ & & \\
\hline & Missing & 180 & $74(67-80)$ & 2.4 & & 44 & $65(56-75)$ & 2.9 & & Missing & 74 & $74(68-82)$ & 1.0 & & 14 & $71(65-77)$ & 0.9 & \\
\hline & I & 768 & $69(63-76)$ & 10.4 & 11.8 & 23 & $69(62-76)$ & 1.6 & 1.9 & Localised & 1,543 & $70(63-76)$ & 20.7 & 22.5 & 52 & $69(60-76)$ & 3.5 & 4.0 \\
\hline & II & 1,245 & $69(62-76)$ & 16.9 & 17.6 & 60 & $69(62-76)$ & 4.0 & 4.2 & Regional & 1,675 & $69(62-76)$ & 22.4 & 21.9 & 246 & $68(62-75)$ & 16.6 & 17.0 \\
\hline & III & 1,450 & $68(61-74)$ & 19.7 & 17.9 & 327 & $68(61-74)$ & 21.8 & 23.1 & Distant & 4,253 & $69(61-76)$ & 56.9 & 55.6 & 1,188 & $69(62-76)$ & 79.9 & 79.0 \\
\hline \multirow[t]{6}{*}{ Ireland $\boldsymbol{q}$} & patients & 2,484 & $69(62-76)$ & & & 547 & $68(61-75)$ & & & All patients & 2,484 & $69(62-76)$ & & & 547 & $68(61-75)$ & & \\
\hline & Missing & 310 & $73(64-81)$ & 12.5 & & 96 & $71(63-78)$ & 17.6 & & Missing & 148 & $76(66-82)$ & 6.0 & & 48 & $72(60-79)$ & 8.8 & \\
\hline & I & 358 & $69(62-75)$ & 16.5 & 16.9 & 11 & $65(57-73)$ & 2.4 & 2.6 & Localised & 632 & $69(63-77)$ & 27.1 & 28.4 & 27 & $69(65-75)$ & 5.4 & 6.2 \\
\hline & II & 433 & $70(63-77)$ & 19.9 & 20.5 & 33 & $69(63-80)$ & 7.3 & 8.1 & Regional & 745 & $69(62-76)$ & 31.9 & 31.5 & 155 & $69(62-76)$ & 31.1 & 30.7 \\
\hline & III & 540 & $69(62-76)$ & 24.8 & 24.8 & 132 & $68(61-75)$ & 29.3 & 30.3 & Distant & 959 & $68(61-75)$ & 41.1 & 40.1 & 317 & $67(60-74)$ & 63.5 & 63.1 \\
\hline & IV & 843 & $68(61-75)$ & 38.8 & 37.8 & 275 & $67(60-74)$ & 61.0 & 58.9 & & & & & & & & & \\
\hline $\begin{array}{l}\text { New } \\
\text { Zealand }\end{array}$ & $\begin{array}{l}\text { All } \\
\text { patients }\end{array}$ & & & & & & & & & All patients & 3,126 & $68(61-75)$ & & & 570 & 67 (59-74) & & \\
\hline & Missing & & & & & & & & & Missing & 954 & $70(63-77)$ & 30.5 & & 177 & $68(59-73)$ & 31.1 & \\
\hline & I & & & & & & & & & Localised & 270 & $68(62-73)$ & 12.4 & 13.3 & 3 & $72(67-75)$ & 0.8 & $0.8^{*}$ \\
\hline & II & & & & & & & & & Regional & 456 & $67(60-73)$ & 21.0 & 24.4 & 82 & $67(58-74)$ & 20.9 & $20.9^{*}$ \\
\hline & III & & & & & & & & & Distant & 1,446 & $67(59-75)$ & 66.6 & 62.3 & 308 & 67 (59-74) & 78.4 & $78.4^{*}$ \\
\hline & $\begin{array}{l}\text { IV } \\
\text { All }\end{array}$ & & & & & & & & & & & & & & & & & \\
\hline Norway & patients & 4,128 & $69(62-76)$ & & & 1,029 & $68(61-75)$ & & & All patients & 4,128 & $68(61-75)$ & & & 1,029 & $68(61-75)$ & & \\
\hline & Missing & 895 & $69(63-77)$ & 21.7 & & 354 & $68(62-75)$ & 34.4 & & Missing & 89 & $69(64-78)$ & 2.2 & & 29 & 75 (67-78) & 2.8 & \\
\hline & I & 589 & $68(63-75)$ & 18.2 & 17.5 & 26 & $65(60-73)$ & 3.9 & 3.3 & Localised & 1,067 & $69(64-76)$ & 26.4 & 25.9 & 85 & $68(59-75)$ & 8.5 & 8.0 \\
\hline & II & 601 & $69(63-75)$ & 18.6 & 17.7 & 48 & $65(59-75)$ & 7.1 & 6.4 & Regional & 1,215 & $69(62-76)$ & 30.1 & 31.4 & 285 & $67(60-73)$ & 28.5 & 30.6 \\
\hline & III & 677 & $69(62-76)$ & 20.9 & 20.4 & 167 & $67(59-73)$ & 24.7 & 26.1 & Distant & 1,757 & $68(61-76)$ & 43.5 & 42.6 & 630 & $68(62-75)$ & 63.0 & 61.4 \\
\hline
\end{tabular}




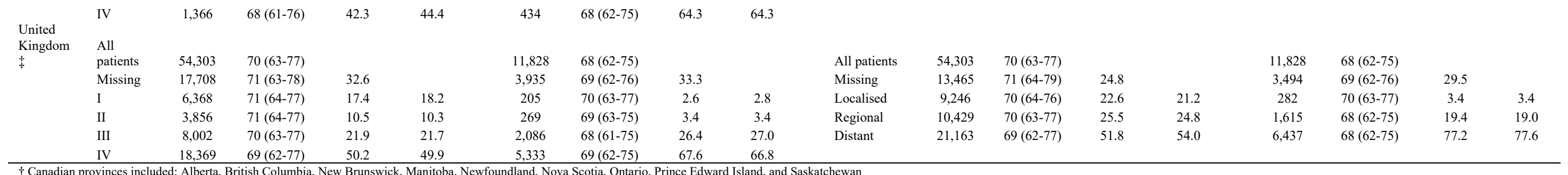

$\dagger$ Canadian provinces included: Alberta, British Columbia, New Brunswick, Manitoba, Newfoundland, Nova Scotia, Ontario, Prince Edward Island, and Saskatchewan United Kingdom registries included: England, Northern Ireland, Scotland, and Wales

II Ireland: 2010-2013

* Model did not converge 
For all stages combined, the age-standardised 1-year net survival for NSCLC among males was highest for Canada (48.1\%) and lowest for Ireland (41.8\%), New Zealand (41.5\%) and the UK (40.8\%) (Figure 2A, Supplementary Table 11). The 3-year net survival rates showed a similar pattern (between $19.7 \%$ and $27.1 \%$ ). For females, the range was slightly wider for 1-year and 3year net survival (between $48.3 \%$ and $57.8 \%$, and 25.3 and $35.0 \%$, respectively) (Figure 2A, Supplementary Table 12).

Sex-specific net survival varied substantially depending on stage at diagnosis, with little consistency in the ranking of countries at both 1-year and 3-years after diagnosis (Figure 3A, Supplementary Tables 11-12). For example, for males, Australia had the lowest 1-year net survival for localised tumours (81.6\%), but the highest 1-year net survival for distant tumours (25.6\%). Nevertheless, we observed that survival for males and females was consistently high across all (SEER) stages for Canada, whilst Ireland and the UK reported consistently lower survival.

Among males and females, both 1-year and 3-year survival for distant SEER stage was highest for Australia and lowest for the UK, respectively. Further, as seen for overall NSCLC, females had higher 1-year and 3-year net survival for all stages at diagnosis. Notable sex differences (i.e. $>10 \%$ point difference) were observed at 1 -year post diagnosis for regional NSCLC in New Zealand ( $\Delta=10.7 \%$ point), Ireland ( $\Delta=12.0 \%$ point), and Norway ( $\Delta=11.4 \%$ point).

Similar differences in stage-specific net survival were observed when using TNM stage (Figure 4A, Supplemental Tables 11-12). Among the five countries that provided TNM stage, 1 -year net survival for NSCLC with TNM stages II and III was significantly lower for males in Ireland, at $69.8 \%$ and $45.3 \%$ respectively, and the UK, at $76.3 \%$ (TNM stage II only), compared to Denmark $(84.4 \%$ for stage II , 56.0\% for stage III ). Amongst cases diagnosed with stage IV disease, 1-year net survival was lowest at $18.8 \%$ for males in the UK, followed by Ireland (19.8\%), Denmark $(21.2 \%)$, Norway $(21.8 \%)$, and finally Canada (23.6\%). As for females, the lowest survival for all stages at both 1-year and 3-years post-diagnosis was observed for the UK and Ireland. The largest absolute differences in net survival between countries were observed for stages II and III, and there was an indication that survival was more homogeneous for stage IV, particularly for 3-year net survival where the absolute difference between Canada (highest) and the UK (lowest) was only 3.7 percentage points. 


\section{Small Cell Lung Carcinoma}

Approximately $70 \%$ of SCLC patients were diagnosed with stage IV or distant disease (Table $2 \mathrm{~A}$ and 2B, Figure 1B), although some variation was observed between countries and sexes; for example, New Zealand had the largest proportion of patients diagnosed with distant disease at $84.3 \%$ for males and $78.4 \%$ for females. Females had a more favourable stage distribution compared to males.

One-year net survival ranged for males from $25.0 \%$ in New Zealand and the UK to $31.8 \%$ in Australia, and for females $31.2 \%$ in the UK to $39.2 \%$ in Canada (Figure 2B, Supplementary Tables 13-14). Canada and Norway had the highest 3-year net survival for both males and females, though differences between the seven countries were minimal. There were large disparities in net survival between sexes, in particular at 1-year after diagnosis, with 1-year net survival for females being 6.2 percentage points (UK) to 10.6 percentage points (Canada) higher than that observed for males.

Differences by SEER stage in net survival between the seven countries were also found (Figure 3B, Supplementary Tables 13-14). Among males with localised SCLC, 1-year net survival was lower in Australia (58.3\%) and Norway (58.6\%) than in Canada (82.2\%) and Denmark (79.5\%). For cases with regional and distant disease, males in Denmark had the highest 1-year net survival at $63.0 \%$ and $24.3 \%$, respectively; whereas for regional disease, 1 -year survival was lowest for males in Ireland and New Zealand, and Norway and New Zealand had the lowest survival for distant cases. Net survival at 3-years among male patients showed similar patterns. For females, 1-year and 3-year net survival was highest in Denmark for most stages. New Zealand and Norway had lower survival for most stages along with Ireland and the UK, though most notable was the low survival observed for females with localised stage in Australia (62.8\%) at one year post diagnosis (Supplementary Table 14).

Net survival by TNM stage is shown in Figure 4B (Supplemental Tables 13-14). In general, similar differences in stage-specific net survival were observed when using TNM stage. For example, for females, 1 -year net survival for stage III SCLC ranged from $49.1 \%$ in Ireland to $56.3 \%$ in Canada; the corresponding 3 -year net survival ranged from $15.6 \%$ in the UK to $24.2 \%$ in Canada. As with NSCLC, the survival differences among the countries investigated were largest for stages II and III. 


\section{Within country differences}

While it was beyond the scope of this manuscript to explore within-country disparities for NSCLC and SCLC survival in detail, the best outcomes in Canada were generally observed for Manitoba and New Brunswick while the worst outcomes were observed for Prince Edward Island and Nova Scotia, although the differences were not always statistically significant due to low statistical power for the latter jurisdictions (Supplemental Tables 6-10, 15-20). In the UK, survival for NSCLC and SCLC appeared to be highest in Scotland for early disease stages, with survival at advanced stages being generally comparable across the four jurisdictions.

\section{DISCUSSION}

In this study, discrepancies in lung cancer survival were evident across countries by sex, histological group and stage, with higher survival observed for Canada and Norway, and lower survival in the UK, New Zealand and Ireland. Survival was consistently higher for females (for all stage and histological groups) and for NSCLC. Variations in stage distribution and stage-specific survival estimates were apparent and may partly explain international survival differences. Net survival within stage groups varied across countries whereby survival was consistently higher across stages of disease for Canada and Denmark, and consistently lower for Ireland and the UK.

A previous study of a similar group of countries reported 1-year net survival among lung cancer cases diagnosed from 2004-2007.2 Despite differences in study methods, generally we obtained similar results with respect to survival differences by histological group and stage, as well as the countries' rankings. Similar findings were also noted in another study investigating lung cancer survival in Europe for 1999-2007, where Ireland and the UK generally exhibited lower survival. ${ }^{15}$ Nonetheless, a decade later, we observed improved survival for lung cancer for all countries, ${ }^{8}$ as well as higher stage-specific survival particularly for NSCLC in this study. However, the contribution of stage migration to the apparent improvement in stage-specific survival cannot be completely ruled out. For example, the migration due to coding stage III to stage IV disease resulting from increased sensitivity and utilization of novel imaging techniques, such as positron emission tomography.

Our findings show that females generally are diagnosed at an earlier stage and have better survival outcomes than men. This is in line with previous studies ${ }^{3-6}$ evaluating the effect of sex on 
lung cancer prognosis and several potential reasons for this observation have been proposed. Firstly, adenocarcinoma lung cancer is the predominant subtype of NSCLC and is more common among females than males. As adenocarcinoma lung cancer is associated with being a never smokers ${ }^{16}$ and having a better response to treatment ${ }^{17}$, we would expect that females would experience better NSCLC survival compared to males because there is a higher proportion of these favourable cases. Secondly, adenocarcinoma that has a wider spectrum of growth rate with some being quite indolent is generally diagnosed at earlier stages compared to other histological types ${ }^{18}$, which corresponds with our finding that a higher proportion of females present with early stage disease, though this may also be due to more frequent and earlier medical consultations. Finally, several studies ${ }^{19-21}$ have also suggested that female sex may be a positive prognostic factor in itself ${ }^{21} 22$, irrespective of age, stage, period of diagnosis and histological groups. Further, mutations in epidermal growth factor receptor have been shown to be more prevalent in females, which may lead to survival advantages. ${ }^{23,24}$

Net survival for SCLC was consistently lower compared to that for NSCLC in all countries. This corresponds with the fact that SCLC tends to grow and spread faster than NSCLC, exemplified by previous research that found larger proportions of individuals with SCLC compared with NSCLC diagnosed at advanced stage or with co-morbid illnesses, which may lead to fewer patients being considered for curative treatment. ${ }^{25}$ For example, in Norway, only $1.7 \%$ of patients with SCLC received surgery compared to $18.1 \%$ of those with any lung cancer in the period $2002-$ $2011 .{ }^{26}$ While we observed considerable differences in 1-year net survival across countries for SCLC, disparities were much smaller at 3 years, which may be explained by the high fatality rate of SCLC regardless of available treatments. ${ }^{27}$

Disparities observed for NSCLC between countries may partly relate to varying proportions with squamous cell carcinoma, large cell carcinoma, and adenocarcinoma, together forming the group with NSCLC. For example, for NSCLC, $50 \%$ were adenocarcinomas for Canadian males compared with $40 \%$ for males in the UK with a similar difference for females (62\% versus $51 \%$ respectively). As a result, the UK had a larger proportion of squamous cell carcinomas which are associated with lower survival overall compared to adencarcinoma. ${ }^{28}$ Unfortunately further stratification of the NSCLC by finer histological groupings was not possible due to insufficient statistical power. Similarly, the UK and New Zealand had larger proportions with NSCLC and SCLC diagnosed at later stages compared to other countries suggesting that countries like 
Canada may detect cancers earlier, although a formal recommendation for lung cancer screening was made in Canada after our study period in 2016. ${ }^{29}$

Although differences in stage distribution will account for some of the survival disparities between countries, differences in stage-specific survival were also evident across countries in our study. These absolute differences were most pronounced for localised and regional stage disease, and may relate to the variability in treatment and management. For example, as surgical resection offers the only realistic chance of cure for lung cancer, ${ }^{30}$ differences in rates of surgery may partly explain survival differences in patients with localised and regional lung cancer. Differences in prehabilitation prior to lung cancer surgery or age at diagnosis across countries are other factors that may explain the observed survival differences. ${ }^{31}$ For example, the median age of patients with NSCLC in the UK was generally higher than that for other countries at each cancer stage. Previous studies have shown that patients at older ages are more likely to have comorbid conditions, which are known predictors of treatment decisions and poorer outcomes including survival. ${ }^{32}$ Whilst historically only around $9 \%$ of NSCLC patients in the UK underwent surgery, the current percentage is 18\% according to the National Lung Cancer Audit 2018 annual report, which is above the national standard. ${ }^{33}$ Combined with the other improvements in lung cancer care in the UK, including recent adoption of immunotherapy and increases in pathological confirmation of cancer and overall cancer care ${ }^{33}$, we expect to see improvements in stage-specific survival in the next ICBP iteration.

A strength of our study is that all data are from high-quality population-based cancer registries, which were additionally standardised and checked using a predefined protocol. All results were validated and interpreted with the input of local experts, including registry experts, epidemiologists and clinicians from each country. Yet, a number of limitations should be noted. First, there is still a substantial proportion of cases with unknown histology, ranging between $11 \%$ and $29 \%$ across the seven countries. While survival for these cases is typically lower than for cases with known histology, the size of this group might have affected survival estimates for SCLC and NSCLC. In a complementary paper, we showed that while the proportion of lung cancer cases with unknown histology has an impact on survival estimates for "known" histology groups, the inclusion and/or reallocation of these individuals does not change international rankings or overall patterns we see across countries ${ }^{34}$. Second, when mapping information from different staging systems, there is potential for misclassification, which might have affected the reported stage distributions and corresponding survival estimates. When analyses were restricted to cases with both SEER and 
TNM information, discrepancies in the final summary stage were found for $8 \%$ of all cases and this affected the estimated survival for localised and regional stage disease only (results not shown). Nonetheless, differences in cancer registration practices and staging systems used should be taken into account when interpreting the results of this paper. ${ }^{35}$ Finally, missing information on stage at diagnosis presents another potential concern when conducting survival comparisons by stage across countries. To some extent, we mitigated the issue of differential missingness across countries by running imputation models separately by country (or jurisdiction) and by including measures of survival time in the models. In sensitivity analyses, we showed that both approaches (with and without imputation) led to very similar results. Yet, there are factors that cannot be taken into account in multiple imputation models that may influence missingness of stage information such as differences in registration practices ${ }^{36}$ and this may have affected our results. Including information such as comorbidity or performance status may improve the imputation and also further our understanding on the causes of survival difference by stage across countries.

In conclusion, this study provides more recent estimates of stage-specific lung cancer survival for seven high-income countries with comparison for the two main histological types and investigating differences by sex. Whilst wide international disparities in lung cancer survival persist, this study illustrates the favourable prognosis for NSCLC cases and early stage lung cancers for females. It is also evident that differences in stage distribution across sex groups, histological types and countries partly explain better lung cancer survival, yet international differences were also observed for stage-specific survival suggesting that factors linked to disease treatment and management, such as rates of high-quality surgery, utilisation of targeted therapy or rehabilitation with increased focus on smoking and physical activity, may be contributing to international disparities in lung cancer survival. As the largest disparities were noted for regional stage disease, the opportunity for intervention may be greatest for this group. Finally, it is recommended that efforts should be made, and resources allocated, to improve the availability and comparability of stage data across countries. This will enable further research to understand the reasons behind international differences in stage-specific survival, which may fuel policy development and optimise prognosis.

\section{ACKNOWLEDGMENTS}


The authors would like to thank the ICBP management team of Cancer Research UK for managing the program, the ICBP SurvMark-2 Local Leads for advice to understand the data, for their contributions to the study protocol and interpretation of the results and the ICBP Clinical Committees for their advice. We are also grateful to the ICBP SurvMark-2 Academic Reference Group for providing independent peer review and advice for the study protocol and analysis plan development. Finally we are thankful to the ICBP Program Board for their oversight and direction.

ICBP SurvMark-2 Local Leads:

Alana Little, Cancer Institute NSW, Alexandria, New South Wales, Australia;

Angela Eckstrand, Alberta Health Services, Edmonton, Alberta, Canada;

Anna Gavin, Northern Ireland Cancer Registry, Queen's University Belfast, Belfast, Northern Ireland, United Kingdom;

Bin Zhang, Government of New Brunswick, Fredericton, New Brunswick, Canada;

Bjørn Møller, Cancer Registry of Norway (Kreftregisteret), Oslo, Norway;

Carol McClure, Government of Prince Edward Island, Charlottetown, Prince Edward Island, Canada;

Rebecca Thomas, Welsh Cancer Intelligence \& Surveillance Unit, Public Health Wales, Cardiff, Wales, United Kingdom;

Connie Marano, Cancer Care Ontario, Toronto, Ontario, Canada

Christine Bertrand, Government of Quebec, Montreal, Quebec, Canada;

Christopher Jackson, Cancer Society of New Zealand, Wellington, New Zealand;

Claire Austin, Ministry of Health, New Zealand

David Gavin, The BC Cancer Research Centre, Vancouver, British Columbia, Canada;

David S Morrison, Scottish Cancer Registry, University of Glasgow, Scotland;

Deirdre Fitzpatrick, Northern Ireland Cancer Registry, Queen's University Belfast, Belfast, Northern Ireland, United Kingdom;

Donna Turner, CancerCare Manitoba, Winnipeg, Manitoba, Canada;

Dyfed Huws, Welsh Cancer Intelligence \& Surveillance Unit, Public Health Wales, Cardiff, Wales, United Kingdom;

Eshwar Kumar, Government of New Brunswick, Fredericton, New Brunswick, Canada;

Gail Noonan, CancerCare Manitoba, Winnipeg, Manitoba, Canada;

Geoff Porter, Canadian Partnership Against Canada, Toronto, Ontario, Canada; 
Gerda Engholm, Survelliance and Pharmacoepidemiology, Danish Cancer Society Research Centre, Copenhagen, Denmark;

Gina Lockwood, Canadian Partnership Against Canada, Toronto, Ontario, Canada;

Grace Musto, CancerCare Manitoba, Winnipeg, Manitoba, Canada;

Grlica Bolesnikov, Government of New Brunswick, Fredericton, New Brunswick, Canada;

Guillaume Ruel, Government of Quebec, Montreal, Quebec, Canada;

Hanna Tervonen, Cancer Institute NSW, Alexandria, New South Wales, Australia;

Hazem Abd Elkader, Cancer Society of New Zealand, Wellington, New Zealand;

Heather Stuart-Panko, Saskatchewan Cancer Agency, Regina, Saskatchewan, Canada;

Janet Warlow, Welsh Cancer Intelligence \& Surveillance Unit, Public Health Wales, Cardiff, Wales, United Kingdom;

Jason Poole, Public Health England, London, England, United Kingdom;

John Spinelli, The BC Cancer Research Centre, Vancouver, British Columbia, Canada;

Lorraine Shack, Alberta Health Services, Edmonton, Alberta, Canada;

Louise Sandford, Cancer Society of New Zealand, Wellington, New Zealand;

Marianne Brenn Jerm (Cancer Registry of Norway (Kreftregisteret), Oslo, Norway

Maureen MacIntyre, Nova Scotia Health Authority, Halifax, Nova Scotia, Canada;

Nathalie St-Jacques, Nova Scotia Health Authority Cancer Care Program, Halifax, Nova Scotia, Canada;

Oliver Bucher, CancerCare Manitoba, Winnipeg, Manitoba, Canada

Paul Walsh, National Cancer Registry Ireland, Cork, Ireland;

Prithwish De, Cancer Care Ontario, Toronto, Ontario, Canada;

Raman Agnihotram, Research-Institude, McGill University Health Centre, Montreal, Quebec, Canada;

Richard Trevithick, Department of Health, Perth, Western Australia, Australia;

Rory Carle, Department of Health, Perth, Western Australia, Australia;

Ryan Woods, Cancer Control Research, BC Cancer, Vancouver, British Columbia, Canada

Sally Vernon, Public Health England, London, England, United Kingdom;

Serena Kozie, Saskatchewan Cancer Agency, Regina, Saskatchewan, Canada;

Susan Ryan, Eastern Health, St. John's, Newfoundland and Labrador, Canada; 
Sue Evans, Cancer Council Victoria, Melbourne, Victoria, Australia;

ICBP SurvMark-2 Academic Reference Group:

Dianne O'Connell, Cancer Council New South Wales, Sydney, New South Wales, Australia;

Michael Eden, Public Health England, London, United Kingdom;

Mark Elwood, University of Auckland, New Zealand

Sabine Siesling (Netherlands Comprehensive Cancer Organisation (IKNL), Utrecht Amsterdam, The Netherlands) and University of Twente, Enschede, The Netherlands).

ICBP Clinical Committee - Lung:

Anur Guhan, The Ayr Hospital, Scotland, United Kingdom;

Christian Finley, McMaster University, Canadian Association of Thoracic Surgeons, Canada;

Brian McCaughan, University of Sydney, Australia;

David Baldwin, University of Nottingham, United Kingdom;

Erik Jakobsen, Odense University Hospital, Denmark;

Ian Williamson, Aneurin Bevan University Hospital, Wales, United Kingdom;

Jason Lester, Velindre Cancer Centre, Wales, United Kingdom;

Jonathan McAleese, Belfast City Hospital, Northern Ireland, United Kingdom;

Karl Kolbeck, Karolinska University Hospital, Sweden;

Mick Peake, Public Health England, United Kingdom;

Odd Terje Brustugun, Oslo University Hospital, Norway;

Paul Dawkins, Middlemore Hospital, New Zealand;

Wendy Anderson, Northern Health and Social Care Trust, Northern Ireland, United Kingdom;

\section{STATEMENTS}

a. Authors contributorship

MAr and MMF-B analysed the data and drafted and revised the paper. MA, MR and AB wrote the statistical analysis plan, monitored data collection for the study, and revised the draft paper, JF prepared the study protocol, monitored data collection and data harmonisation for the study, and revised the draft paper, OB, PD, GE, AG, SK, AL, BM, NSJ, HT, PW, RW prepared the study 
protocol, collected the data, contributed to the analytical plan and revised the draft of the paper, DOC, DB, ME, SS commented on the analytical plan, study results and revised the draft of the paper, FB and IS designed study, data collection tools, monitored data collection for the study, wrote the statistical analysis plan, and drafted and revised the paper. IS is the guarantor of the study.

b. Funding

The project is funded by the International Cancer Benchmarking Partnership which is funded by the Canadian Partnership Against Cancer; Cancer Council Victoria; Cancer Institute New South Wales; Cancer Research UK; Danish Cancer Society; National Cancer Registry Ireland; The Cancer Society of New Zealand; NHS England; Norwegian Cancer Society; Public Health Agency Northern Ireland, on behalf of the Northern Ireland Cancer Registry; The Scottish Government; Western Australia Department of Health; Wales Cancer Network.

\section{c. Competing interests}

The authors declare no relevant competing interests

\section{d. Exclusive license}

IS, the Submitting Author has the right to grant and does grant on behalf of all authors of the Work (as defined in the below author licence), an exclusive licence and/or a non-exclusive licence for contributions from authors who are: i) UK Crown employees; ii) where BMJ has agreed a CC BY licence shall apply, and/or iii) in accordance with the terms applicable for US Federal Government officers or employees acting as part of their official duties; on a worldwide, perpetual, irrevocable, royalty-free basis to BMJ Publishing Group Ltd ("BMJ") its licensees and where the relevant Journal is co-owned by BMJ to the co-owners of the Journal, to publish the Work in THORAX and any other BMJ products and to exploit all rights, as set out in our licence

\section{e. Ethics statement}

The study has been approved by the IARC ethical committee. Meeting reference: EC 2016-04; and Project reference: 16-36.

\section{DICLAIMER}

Where authors are identified as personnel of the International Agency for Research on Cancer / World Health Organization, the authors alone are responsible for the views expressed in this 
article and they do not necessarily represent the decisions, policy or views of the International Agency for Research on Cancer / World Health Organization.

\section{LIST OF TABLES AND FIGURES}

Table 3. Characteristics of patients diagnosed with lung cancer during 2010-2014

Table 2A. Number and proportion of male patients with non-small cell lung carcinoma (NSCLC) and small cell lung carcinoma (SCLC) diagnosed during 2010-2014 by country and stage at diagnosis (TNM and SEER), before and after imputation

Table 2B. Number and proportion of female patients with non-small cell lung carcinoma (NSCLC) and small cell lung carcinoma (SCLC) diagnosed during 2010-2014 by country and stage at diagnosis (TNM and SEER), before and after imputation

Figure 1. Distribution of (imputed) stage at diagnosis of $A$ ) non-small cell lung carcinoma and $B$ ) small cell lung carcinoma by sex and country, 2010-2014

Figure 2. One- and three-year age-standardised ${ }^{*}$ net survival of $\left.A\right)$ non-small cell lung carcinoma and B) small cell lung carcinoma by sex and country, 2010-2014

Figure 3. One- and three-year age-standardised* net survival of A) non-small cell lung carcinoma and B) small cell lung carcinoma by (imputed) SEER stage, sex and country, 2010-2014

Figure 4. One- and three-year age-standardised* net survival of $A$ ) non-small cell lung carcinoma and B) small cell lung carcinoma by (imputed) TNM stage, sex and country, 2010-2014

\section{REFERENCES}

1. Bray F, Ferlay J, Soerjomataram I, et al. Global cancer statistics 2018: GLOBOCAN estimates of incidence and mortality worldwide for 36 cancers in 185 countries. CA Cancer J Clin 2018;68(6):394-424. doi: 10.3322/caac.21492 [published Online First: 2018/09/13]

2. Walters S, Maringe C, Coleman MP, et al. Lung cancer survival and stage at diagnosis in Australia, Canada, Denmark, Norway, Sweden and the UK: a population-based study, 2004-2007. Thorax 2013;68(6):551-64. doi: 10.1136/thoraxjnl-2012-202297 [published Online First: 2013/02/13]

3. Minami H, Yoshimura M, Miyamoto Y, et al. Lung cancer in women: sex-associated differences in survival of patients undergoing resection for lung cancer. Chest 2000;118(6):1603-9. doi: 10.1378/chest.118.6.1603 [published Online First: 2000/12/15]

4. Moore R, Doherty D, Chamberlain R, et al. Sex differences in survival in non-small cell lung cancer patients 1974-1998. Acta Oncol 2004;43(1):57-64. [published Online First: 2004/04/08]

5. Johnson BE, Steinberg SM, Phelps R, et al. Female Patients with Small Cell Lung-Cancer Live Longer Than Male-Patients. Am J Med 1988;85(2):194-96. 
6. Ouellette D, Desbiens G, Emond C, et al. Lung cancer in women compared with men: stage, treatment, and survival. Ann Thorac Surg 1998;66(4):1140-3; discussion 43-4. doi: 10.1016/s00034975(98)00557-8 [published Online First: 1998/11/04]

7. Coleman MP, Forman D, Bryant H, et al. Cancer survival in Australia, Canada, Denmark, Norway, Sweden, and the UK, 1995-2007 (the International Cancer Benchmarking Partnership): an analysis of population-based cancer registry data. Lancet 2011;377(9760):127-38. doi: 10.1016/S0140-6736(10)62231-3 [published Online First: 2010/12/25]

8. Arnold M, Rutherford MJ, Bardot A, et al. Progress in cancer survival, mortality, and incidence in seven high-income countries 1995-2014 (ICBP SURVMARK-2): a population-based study. Lancet Oncol 2019;20(11):1493-505. doi: 10.1016/S1470-2045(19)30456-5 [published Online First: 2019/09/16]

9. Walters S, Maringe C, Butler J, et al. Comparability of stage data in cancer registries in six countries: lessons from the International Cancer Benchmarking Partnership. Int J Cancer 2013;132(3):67685. doi: 10.1002/ijc.27651 [published Online First: 2012/05/25]

10. Sobin LH, Gospodarowicz MK, Wittekind C. TNM classification of malignant tumors. . 7th ed. Oxford: Wiley-Blackwell 2010.

11. Perme MP, Stare J, Esteve J. On estimation in relative survival. Biometrics 2012;68(1):113-20. doi: 10.1111/j.1541-0420.2011.01640.x [published Online First: 2011/06/22]

12. Corazziari I, Quinn M, Capocaccia R. Standard cancer patient population for age standardising survival ratios. Eur J Cancer 2004;40(15):2307-16. doi: 10.1016/j.ejca.2004.07.002 [published Online First: 2004/09/30]

13. Campion WM. Multiple Imputation for Nonresponse in Surveys - Rubin,Db. J Marketing Res 1989;26(4):485-86. doi: Doi 10.2307/3172772

14. LP S. Texas, USA.

15. Francisci S, Minicozzi P, Pierannunzio D, et al. Survival patterns in lung and pleural cancer in Europe 1999-2007: Results from the EUROCARE-5 study. Eur J Cancer 2015;51(15):2242-53. doi: 10.1016/j.ejca.2015.07.033 [published Online First: 2015/10/01]

16. Freedman ND, Leitzmann MF, Hollenbeck AR, et al. Cigarette smoking and subsequent risk of lung cancer in men and women: analysis of a prospective cohort study. Lancet Oncol 2008;9(7):64956. doi: 10.1016/S1470-2045(08)70154-2 [published Online First: 2008/06/17]

17. Nordquist LT, Simon GR, Cantor A, et al. Improved survival in never-smokers vs current smokers with primary adenocarcinoma of the lung. Chest 2004;126(2):347-51. doi: 10.1378/chest.126.2.347 [published Online First: 2004/08/11]

18. Ten Haaf K, van Rosmalen J, de Koning HJ. Lung cancer detectability by test, histology, stage, and gender: estimates from the NLST and the PLCO trials. Cancer Epidemiol Biomarkers Prev 2015;24(1):154-61. doi: 10.1158/1055-9965.EPI-14-0745

19. Visbal AL, Williams BA, Nichols FC, et al. Gender differences in non-small-cell lung cancer survival: An analysis of 4,618 patients diagnosed between 1997 and 2002. Annals of Thoracic Surgery 2004;78(1):209-15. doi: 10.1016/j.athoracsur.2003.11.021

20. de Perrot M, Licker M, Bouchardy C, et al. Sex differences in presentation, management, and prognosis of patients with non-small cell lung carcinoma. $J$ Thorac Cardiovasc Surg 2000;119(1):21-6. doi: 10.1016/s0022-5223(00)70213-3 [published Online First: 1999/12/29]

21. Sagerup CM, Smastuen M, Johannesen TB, et al. Sex-specific trends in lung cancer incidence and survival: a population study of 40,118 cases. Thorax 2011;66(4):301-7. doi: 10.1136/thx.2010.151621 [published Online First: 2011/01/05]

22. Radkiewicz C, Dickman PW, Johansson ALV, et al. Sex and survival in non-small cell lung cancer: A nationwide cohort study. PLoS One 2019;14(6):e0219206. doi: 10.1371/journal.pone.0219206

23. Toyooka S, Takano T, Kosaka T, et al. Epidermal growth factor receptor mutation, but not sex and smoking, is independently associated with favorable prognosis of gefitinib-treated patients with lung adenocarcinoma. Cancer Sci 2008;99(2):303-8. doi: 10.1111/j.1349-7006.2007.00688.x [published Online First: 2008/02/15] 
24. Yang WC, Xiao F, Shih JY, et al. Epidermal growth factor receptor mutation predicts favorable outcomes in non-small cell lung cancer patients with brain metastases treated with stereotactic radiosurgery. Radiother Oncol 2018;126(2):368-74. doi: 10.1016/j.radonc.2017.10.010 [published Online First: 2017/11/08]

25. Koinis F, Kotsakis A, Georgoulias V. Small cell lung cancer (SCLC): no treatment advances in recent years. Transl Lung Cancer $R$ 2016;5(1):39-50. doi: 10.3978/j.issn.2218-6751.2016.01.03

26. Nilssen Y, Strand TE, Fjellbirkeland L, et al. Lung cancer treatment is influenced by income, education, age and place of residence in a country with universal health coverage. Int J Cancer 2016;138(6):1350-60. doi: 10.1002/ijc.29875 [published Online First: 2015/10/01]

27. Glisson BS, Hong WK. Survival after treatment of small-cell lung cancer: an endless uphill battle. $J$ Natl Cancer Inst 1997;89(23):1745-7. doi: 10.1093/jnci/89.23.1745 [published Online First: $1997 / 12 / 10]$

28. Kawase A, Yoshida J, Ishii G, et al. Differences between squamous cell carcinoma and adenocarcinoma of the lung: are adenocarcinoma and squamous cell carcinoma prognostically equal? Jpn J Clin Oncol 2012;42(3):189-95. doi: 10.1093/jjco/hyr188 [published Online First: 2012/01/03]

29. Canadian Task Force on Preventive Health C. Recommendations on screening for lung cancer. CMAJ 2016;188(6):425-32. doi: 10.1503/cmaj.151421 [published Online First: 2016/03/10]

30. Woolhouse I. Variation in lung cancer outcomes in the UK and Europe. Clin Med (Lond) 2011;11(2):110-1. doi: 10.7861/clinmedicine.11-2-110 [published Online First: 2011/04/30]

31. Boujibar F, Bonnevie T, Debeaumont D, et al. Impact of prehabilitation on morbidity and mortality after pulmonary lobectomy by minimally invasive surgery: a cohort study. $J$ Thorac Dis 2018;10(4):2240-48. doi: 10.21037/jtd.2018.03.161 [published Online First: 2018/06/01]

32. Gould MK, Munoz-Plaza CE, Hahn EE, et al. Comorbidity Profiles and Their Effect on Treatment Selection and Survival among Patients with Lung Cancer. Ann Am Thorac Soc 2017;14(10):157180. doi: 10.1513/AnnalsATS.201701-030OC [published Online First: 2017/05/26]

33. Physicians; RCo. National Lung Cancer Audit annual report 2018 (for the audit period 2017). London: Royal College of Physicians, 2019.

34. Morgan E, Arnold M, Rutherford M, et al. The impact of reclassifying cancers of unspecified histology on international differences in survival for small cell and non-small cell lung cancer Int J Cancer 2021 (epub)

35. Pineros M, Parkin DM, Ward K, et al. Essential TNM: a registry tool to reduce gaps in cancer staging information. Lancet Oncol 2019;20(2):e103-e11. doi: 10.1016/S1470-2045(18)30897-0 [published Online First: 2019/02/05]

36. O'Dowd EL, McKeever TM, Baldwin DR, et al. What characteristics of primary care and patients are associated with early death in patients with lung cancer in the UK? Thorax 2015;70(2):161-8. doi: 10.1136/thoraxjnl-2014-205692 